\title{
Synthesis and Characterization of Yttrium Stabilized Zirconia Nanoparticles
}

\author{
Thirupathy Maridurai ${ }^{a}$, Dhanapal Balaji ${ }^{b}$, Suresh Sagadevan ${ }^{c *}$ \\ ${ }^{a}$ Department of Production Engineering, Velammal Engineering College, Chennai 600066 , India \\ ${ }^{b}$ Department of Automobile Engineering, Velammal Engineering College, Chennai 600 066, India \\ ${ }^{c}$ Department of Physics, AMET University, Chennai 603 112, India
}

Received: March 5, 2016; Revised: April 20, 2016; Accepted: May 23, 2016

\begin{abstract}
Yttria stabilized zirconia (YSZ) nanoparticles were synthesized by the co-precipitation method. The crystallinity, morphological and optical properties of the YSZ nanoparticles were studied by using X-ray diffraction (XRD), scanning electron microscopy (SEM), transmission electron microscopy (TEM), FT-Raman, photoluminescence (PL) spectrum analyses. The grain size and crystal structure of the YSZ was confirmed by XRD. SEM and TEM analyses showed that the synthesized samples were composed of the size of nanometers. The optical property of the synthesized nanoparticles was studied from the photoluminescence spectrum. The dielectric properties such as the dielectric constant, the dielectric loss and AC conductivity of the YSZ nanoparticles were studied in the different frequencies and temperature.
\end{abstract}

Keywords: Yttria stabilized zirconia, Nanoparticles, FT-Raman, SEM, TEM, and Dielectric studies

\section{Introduction}

Zirconia $\left(\mathrm{ZrO}_{2}\right)$ nanoparticles have been reported to have unique properties such as excellent refractoriness, chemical resistance, good mechanical strength, high ionic conductivity, low thermal conductivity at high temperature together with relatively high thermal expansion coefficient and good thermal stability ${ }^{1,2}$. A wide-ranging industrial applications including fabrication of dense ceramics, sensors, batteries, capacitors, corrosionresistant and thermal barrier coatings, solid electrolytes for fuel cells, catalysts, etc. have been established ${ }^{3-5}$. It is therefore vital to study the $\mathrm{ZrO}_{2}$ nanoparticles. Pure $\mathrm{ZrO}_{2}$ has three main polymorphs-monoclinic, tetragonal and cubic. The monoclinic form is thermodynamically stable at room temperature but transforms reversibly to the tetragonal structure above $1170^{\circ} \mathrm{C}$. High temperature polymorphs (tetragonal and cubic) have to be stabilized at lower temperature because of their application in various fields, either by adding stabilizers such as $\mathrm{Y}_{2} \mathrm{O}_{3}$, $\mathrm{MgO}$, and $\mathrm{CaO}$ or by reduction in grain or particle size into nanometer regime ${ }^{6}$. Owing to its wide applications and exceptional properties such as high mechanical strength, good chemical stability, high level of oxygenion conductivity, corrosion resistance, low thermal conductivity, and interesting luminescent functions, yttria stabilized zirconia (YSZ) plays an important role among the doped alloys of $\mathrm{ZrO}_{2}^{7-12}$. In the present study, co-precipitation method was employed to prepare the Yttria stabilized zirconia nanoparticles. The structural, spectral optical and electrical properties of the Yttria stabilized zirconia nanoparticles were determined in depth by means of XRD, FT-IR spectroscopy, PL, SEM, TEM, and Dielectric measurements.

* e-mail: sureshsagadevan@gmail.com

\section{Experimental Synthesis}

For the preparation of Yttria stabilized zirconia (YSZ) powders by co-precipitation method, zirconium (IV) acetate hydroxide $\left(\mathrm{C}_{6} \mathrm{H}_{10} \mathrm{O}_{7} \mathrm{Zr}\right)$, yttrium (III) acetate tetrahydrate $\left(\mathrm{C}_{6} \mathrm{H}_{9} \mathrm{O}_{6} \mathrm{Y} \bullet 4 \mathrm{H}_{2} \mathrm{O}\right)$ and oxalic acid dehydrate $\left(\mathrm{C}_{2} \mathrm{H}_{6} \mathrm{O}_{6}\right)$ were used. The stoichiometric amounts of zirconium (IV) acetate hydroxide and yttrium (III) acetate tetrahydrate were dissolved in diluted acetic acid. The obtained solution of Y and Zr salts was slowly poured into aqueous solution of oxalic acid under active stirring at $60^{\circ} \mathrm{C}$ for $20 \mathrm{~min}$. As a result, white opaque colloidal solution was formed.To promote sedimentation, concentrated ammonia solution was added drop-wise to the reaction mixture up to $\mathrm{pH} 9-10$. The precipitate was filtered, washed with distilled water and acetone and then dried for $24 \mathrm{~h}$ at $100^{\circ} \mathrm{C}$ in air. The dried precipitate was ground to fine powder using agate mortar and pestle. The powders were calcined at $700^{\circ} \mathrm{C}$ for $3 \mathrm{~h}$. The XRD pattern of the Yttria stabilized zirconia (YSZ) nanoparticles was noted by using a powder X-ray diffractometer (Schimadzu model: XRD 6000 using $\mathrm{CuK} \alpha(\lambda=0.154 \mathrm{~nm})$ radiation, with a diffraction angle between $20^{\circ}$ and $80^{\circ}$. Scanning Electron Microscopy (SEM) studies were carried out on JEOL, JSM- 67001. Image of Transmission Electron Microscope (TEM) was taken using an H-800 TEM (Hitachi, Japan) with an accelerating voltage of $100 \mathrm{kV}$. Raman spectrum was obtained using a Bruker RFS 27: stand-alone model Raman spectrometer. The photoluminescence (PL) spectrum of the Yttria stabilized zirconia (YSZ) nanoparticles was recorded using the PerkinElmer lambda 900 spectrophotometer with a Xe lamp as the excitation light source. The dielectric - and the dielectric loss of the pellets of Yttria stabilized zirconia nanoparticles in disk form were examined for various frequencies and temperatures. The dielectric properties of the Yttria stabilized zirconia (YSZ) were analyzed over the frequency range $50 \mathrm{~Hz}-5 \mathrm{MHz}$ using a HIOKI 3532-50 LCR HITESTER. 


\section{Results and Discussion}

\subsection{Structural Characterization}

The XRD patterns of the Yttria stabilized zirconia (YSZ) powders are shown in Figure 1. All the diffraction peaks are indexed to the cubic zirconia. However, the characteristics reflections for tetragonal and cubic phases are located and hence the diffraction pattern of YSZ could be attributed to the cubic and tetragonal phases ${ }^{13-16}$. All peaks obtained by XRD analysis were assigned by comparison with data from the Joint Committee on powder Diffraction Standards (JCPDS). The average grain size (D) was calculated using the Scherrer formula,

$$
D=\frac{0.9 \lambda}{\beta \cos \theta}
$$

Where, $\lambda$ is the $\mathrm{X}$-ray wavelength $\left(\mathrm{CuK}_{\alpha}\right.$ radiation and equals to $0.154 \mathrm{~nm}), \theta$ is the Bragg diffraction angle, and $\beta$ is the FWHM (Full Width Half Maxima) of the XRD peak appearing at the diffraction angle $\theta$. The average grain size was calculated from X-ray line broadening using Scherrer equation and it was found to be about $12 \mathrm{~nm}$.

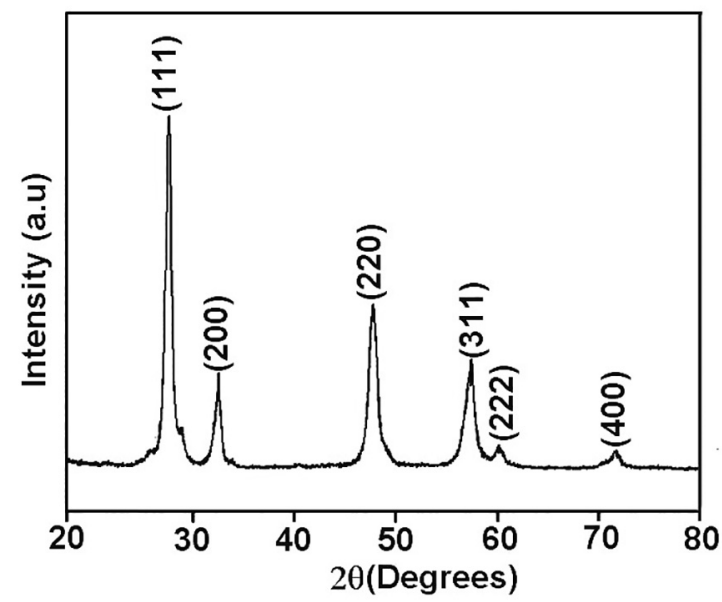

Figure 1: XRD patterns of as synthesized YSZ.

\subsection{Morphological Characterization}

The nanoparticles are in uniform spherical shape and narrow size distribution as revealed by the SEM images shown in Figure 2. Moreover, they confirm good morphology with smaller nanoparticles size. It is seen that equiaxial particles, uniform in shape and size, with a relative tendency of agglomeration are observed. The EDS spectrum shown in Figure 3 confirms the purity and content of the synthesized sample clearly. The atomic ratio of $\mathrm{Zr}$ :Y obtained from the EDS analysis agrees well with the initial composition used for synthesis of the nanomaterial. The TEM micrograph of yttria stabilized zirconia powder is shown in Figure 4. The TEM images indicate that the particles are of uniform size with an average particle size approximately of $17 \mathrm{~nm}$.

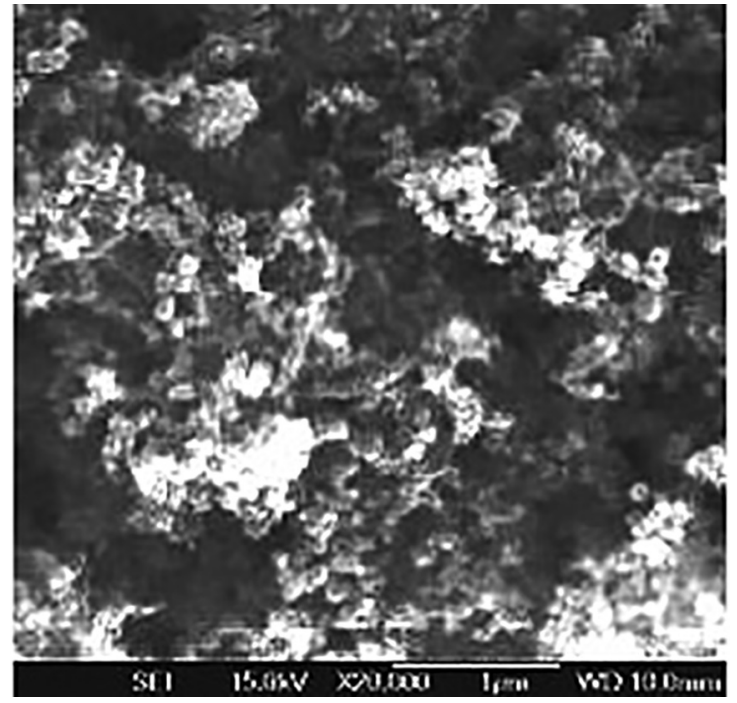

Figure 2: SEM image of YSZ.

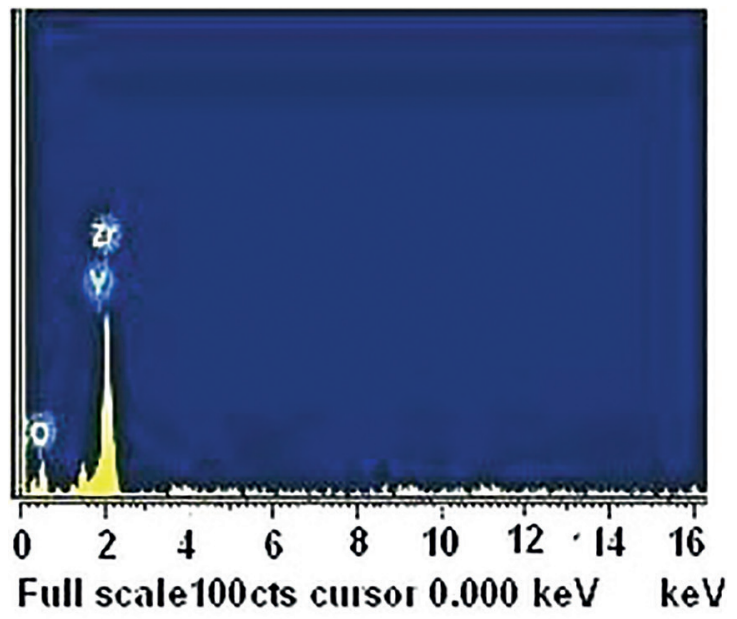

Figure 3: EDS spectrum of YSZ.

\subsection{FT-Raman Analysis}

In the Raman spectrum shown in Figure 5, six prominent peaks corresponding to the Raman-active modes of tetragonal phase are observed for Yttria stabilized zirconia. The peaks are directly related to the $3 \mathrm{E}_{\mathrm{g}}, 2 \mathrm{~B}_{\mathrm{lg}}$, and $1 \mathrm{~A}_{1 \mathrm{~g}}$ symmetries as predicted and reported for the tetragonal phase ${ }^{17,18}$. The Raman spectrum is found to be very similar, except for the observed peak broadening and a slight shift in the $\mathrm{E}_{\mathrm{g}}(2)$ peak to lower frequencies with yttrium dopant concentration.

\subsection{Photoluminescence Studies}

The photoluminescence spectrum was recorded corresponding to an excitation wavelength centered at $293 \mathrm{~nm}$. The PL spectrum of Yttria stabilized zirconia was recorded at room temperature and is given in Figure 6. Yttria doped zirconia, a UV emission centered at $365 \mathrm{~nm}$, an efficient violet emission centered at $400 \mathrm{~nm}$, and a small green emission at $495 \mathrm{~nm}$ were observed. It was found that 


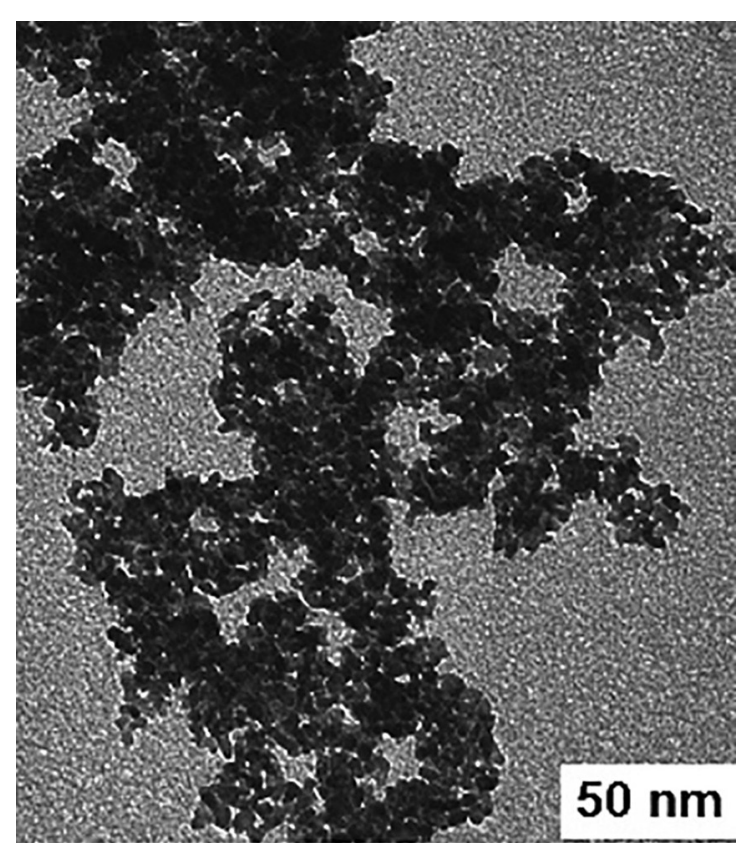

Figure 4: TEM image of YSZ.

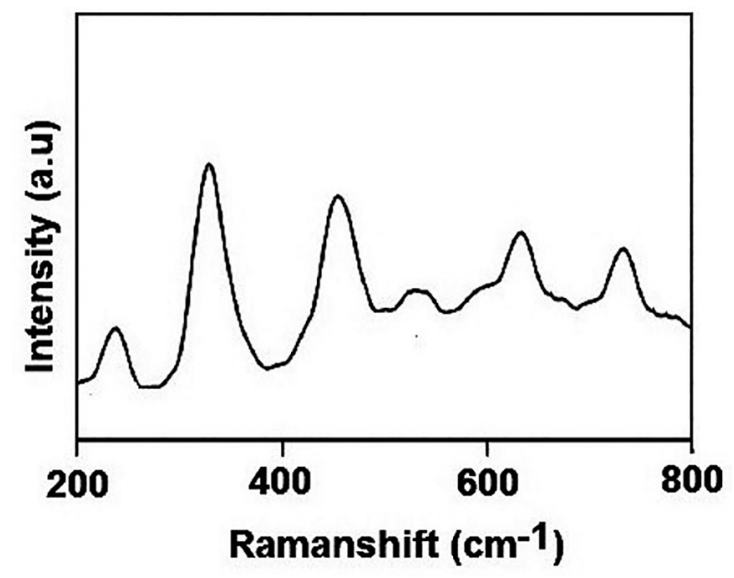

Figure 5: Raman spectrum of YZS.

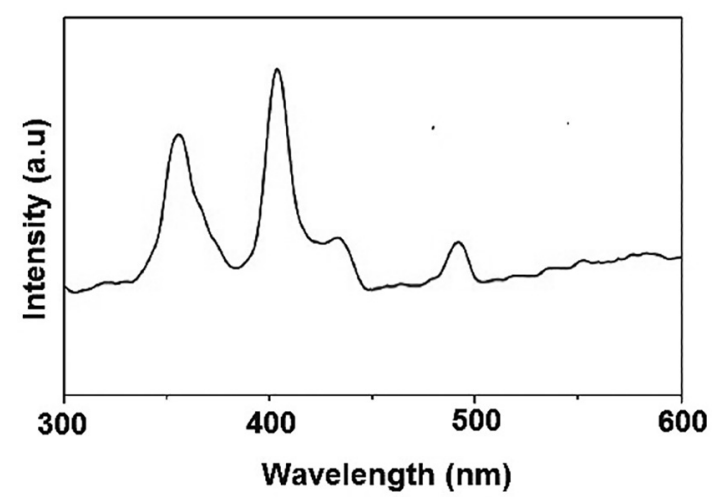

Figure 6: PL spectrum of YSZ the PL excitation band around $293 \mathrm{~nm}$ can be attributed to defect states due to oxygen vacancies that exist at the grain boundaries in the YSZ samples that are an inherent aspect of nanocrystallinity ${ }^{19,20}$.

\subsection{Dielectric Properties}

The variations of dielectric constant with frequency and temperature for YSZ nanoparticles are shown in Figure 7. At low frequencies the dielectric constant of YSZ nanoparticles is high and it decreases rapidly at all temperatures with the applied frequency. It is also observed from the plot that with an increase in the temperature, the dielectric constant increases and this is attributed to the presence of space charge polarization near the grain boundary interfaces, on which the purity and exactness of the sample rely ${ }^{21}$. Hence the dielectric constant of nanostructured materials needs to be larger than that of the conventional materials. Due to the grain boundary interfaces structures the space charge polarization increases and results into the large dielectric constant of nanocrystalline materials at sufficiently high temperature. Figure 8 shows the variations of the dielectric loss of YSZ nanoparticles with frequency and temperature. The dielectric loss decreases when the frequency increases and at higher frequencies the loss angle remains nearly the same at all temperatures. In dielectric materials, generally dielectric losses occur due to absorption current ${ }^{22}$. The orientation of the molecules along the direction of the applied electric field in polar dielectrics requires a part of the electric energy to overcome the forces of internal friction ${ }^{23}$. Another part of the electric energy is utilized for rotations of dipolar molecules and other kinds of molecular transfer from one position to another, which also involves energy losses.

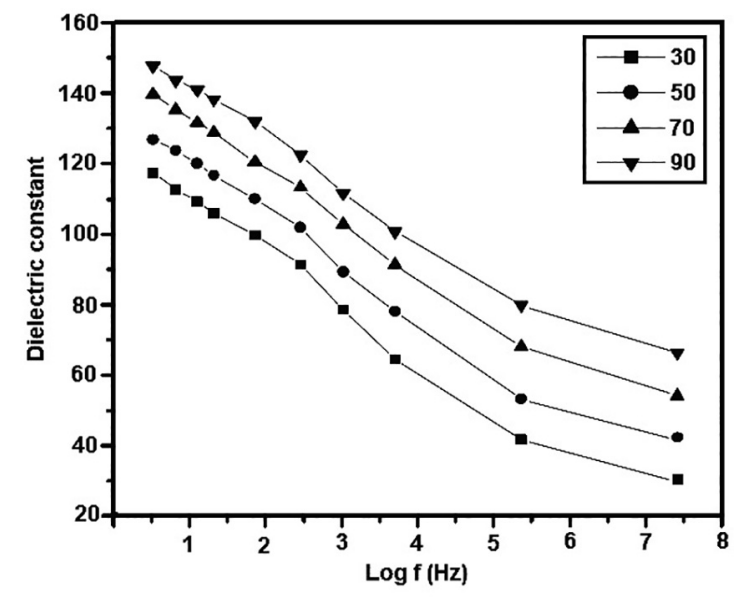

Figure 7: Dielectric constant with log frequency.

\subsection{AC Conductivity studies}

Electrical conduction in Yttria stabilized zirconia nanoparticles takes place as a result of electrons jumping from the low valence state to high valence state as well as the 


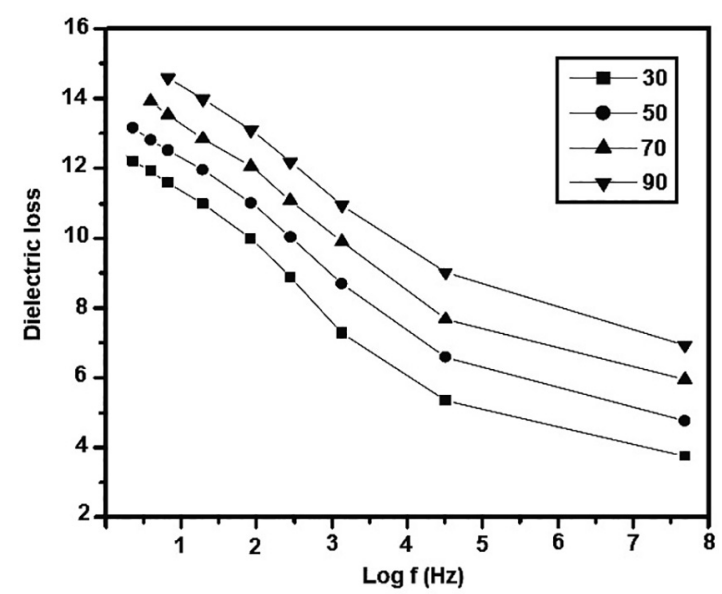

Figure 8: Variation of dielectric loss with log frequency.

movement of ions. The frequency dependence behaviour of the ac conductivity in the temperature interval from $30^{\circ} \mathrm{C}$ to $90^{\circ} \mathrm{C}$ is shown in Figure 9. The ac conductivity increases with the increase in frequency for all temperatures. The increase in frequency enhances the electron hopping frequency and hence it is observed that ac conductivity gradually increases with the increase in frequency of applied ac field. The increased conductivity at higher frequencies could be due to the reduction in space charge polarization ${ }^{24}$.

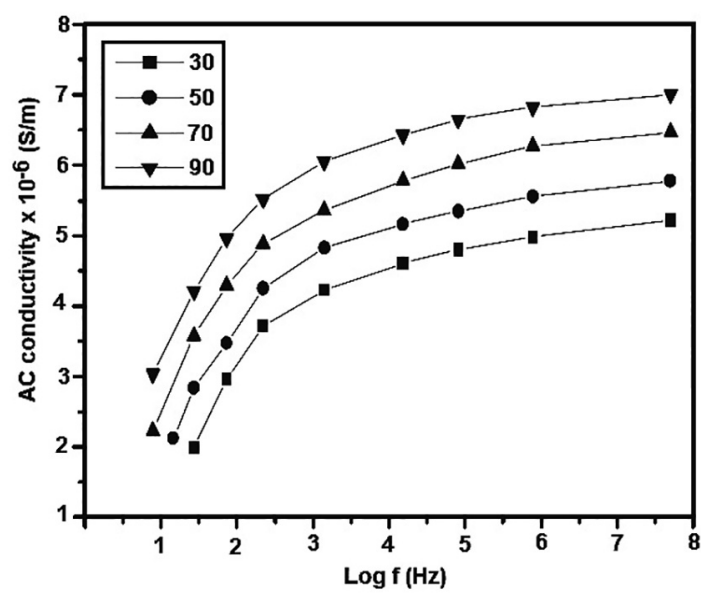

Figure 9: AC conductivity plot for YSZ nanoparticles.

\section{Conclusion}

By using co-precipitation method Yttria stabilized zirconia nanoparticles were synthesized successfully. The structure was confirmed from the XRD pattern. The synthesized samples were ascertained by SEM and TEM analyses and the sizes calculated were in nanometers. The optical properties were studied by using the PL spectrum. The variations of the dielectric constant, the dielectric loss, and AC conductivity with variation in frequency and temperature for YSZ nanoparticles were analyzed. The dielectric studies revealed that both the dielectric constant and the dielectric loss decreased with increase in frequency.
The AC electrical conductivity was found to increase with increase in the temperature and frequency.

\section{References}

1. Tahmasebpour M, Babaluo AA, Razavi Aghjeh MK. Synthesis of zirconia nanopowders from various zirconium salts via polyacrylamide gel method. Journal of the European Ceramic Society. 2008;28(4):773-778. DOI: http://dx.doi.org/10.1016/j. jeurceramsoc.2007.09.018

2. Garcia FL, Resende VG, De Grave E, Peigney A, Barnabé A, Laurent $\mathrm{C}$. Iron-stabilized nanocrystalline $\mathrm{ZrO}_{2}$ solid solutions: Synthesis by combustion and thermal stability. Materials Research Bulletin. 2009;44(6):1301-1311. DOI: http://dx.doi. org/10.1016/j.materresbull.2008.12.014

3. Guo GY, Chen YL. A nearly pure monoclinic nanocrystalline zirconia. Journal of Solid State Chemistry. 2005;178(5):16751682. DOI: http://dx.doi.org/10.1016/j.jssc.2005.03.005

4. Liang J, Jiang X, Liu G, Deng Z, Zhuang J, Li F, et al. Characterization and synthesis of pure $\mathrm{ZrO}_{2}$ nanopowders via sonochemical method. Materials Research Bulletin. 2003;38(1):161-168. DOI: http://dx.doi.org/10.1016/S0025-5408(02)01007-3

5. Sadykov VA, Zaikovskii VI, Zyuzin DA, Moroz EM, Burgina EB, Ishchenko AV. Nanoscale Structural Features of UltrafineZirconia Powders Obtained Via Precipitation-hydrothermal Treatment Route. MRS Proceedings. 2005;878:Y4.8.

6. Chandra N, Singh DK, Sharma M, Upadhyay RK, Amritphale SS, Sanghi SK. Synthesis and characterization of nano-sized zirconia powder synthesized by single emulsion-assisted direct precipitation. Journal of Colloid and Interface Science. 2010;342(2):327-332. PMID: 19942226 DOI: http://dx.doi. org/10.1016/j.jcis.2009.10.065

7. Amézaga-Madrid P, Antúnez-Flores W, González-Hernández J, Sáenz-Hernández J, Campos-Venegas K, Solís-Canto O, et al. Microstructural properties of multi-nano-layered YSZ thin films. Journal of Alloys and Compounds. 2010;495(2):629-633. DOI: http://dx.doi.org/10.1016/j.jallcom.2009.10.257

8. Farhikhteh S, Maghsoudipour A, Raissi B. Synthesis of nanocrystalline $\mathrm{YSZ}\left(\mathrm{ZrO}_{2}-8 \mathrm{Y}_{2} \mathrm{O}_{3}\right)$ powder by polymerized complex method. Journal of Alloys and Compounds. 2010;491(1-2):402-405. DOI: http://dx.doi.org/10.1016/j.jallcom.2009.10.196

9. Oghaz MH, Razavi RS, Loghman-Estark MR, Ghasemi R. Optimization of Morphology and Particle Size of Modified Sol Gel Synthesized YSZ Nanopowder Using Taguchi Method. Journal of Nano Research. 2013;21:65-70. DOI: http://dx.doi. org/10.4028/www.scientific.net/JNanoR.21.65

10. Hajizadeh-Oghaz M, Razavi RS, Khajelakzay M. Optimizing sol-gel synthesis of magnesia-stabilized zirconia (MSZ) nanoparticles using Taguchi robust design for thermal barrier coatings (TBCs) applications. Journal of Sol-Gel Science and Technology. 2015;73(73):227-241. DOI: http://dx.doi. org/10.1007/s10971-014-3521-3

11. Hajizadeh-Oghaz M, Razavi RS, Loghman-Estarki MR. Synthesis and characterization of non-transformable tetragonal YSZ nanopowder by means of Pechini method for thermal barrier coatings (TBCs) applications. Journal of Sol-Gel Science and Technology. 2014;70(1):613. DOI: http://dx.doi.org/10.1007/s10971-014-3266-Z

12. Hajizadeh-Oghaz M, Razavi RS, Ghasemi A. Synthesis and characterization of ceria-yttria co-stabilized zirconia (CYSZ) nanoparticles by sol-gel process for thermal barrier coatings (TBCs). Journal of Sol-Gel Science and Technology. 2015;749(3):603-612. DOI: http://dx.doi.org/10.1007/s10971015-3639-y 
13. Loghman-Estarki MR, Nejati M, Edris H, Razavi RS, Jamali H, Pakseresht AH. Evaluation of hot corrosion behavior of plasma sprayed scandia and yttria co-stabilized nanostructured thermal barrier coatings in the presence of molten sulfate and vanadate salt. Journal of the European Ceramic Society. 2015;35(2):693702. DOI: http://dx.doi.org/10.1016/j.jeurceramsoc.2014.08.029

14. Loghman-Estarki MR, Razavi RS, Edris H, Bakhshi SR, Nejati M, Jamali H. Comparison of hot corrosion behavior of nanostructured Sc YSZ and YSZ thermal barrier coatings. Ceramics International. 2016;42(6):7432-7439. DOI: http:// dx.doi.org/10.1016/j.ceramint.2016.01.147

15. Loghman-Estarki MR, Pourbafrany M, Razavi RS, Edris H, Bakhshi SR, Erfanmanesh M, et al. Preparation of nanostructured YSZ granules by the spray drying method. Ceramics International. 2014;40(2): 3721-3729. DOI: http://dx.doi.org/10.1016/j. ceramint.2013.09.050

16. Loghman-Estarki MR, Razavi RS, Edris H, Pourbafrany M, Jamali H, Ghasemi R. Life time of new SYSZ thermal barrier coatings produced by plasma spraying method under thermal shock test and high temperature treatment. Ceramics International. 2014;40(1 PartB):1405-1414. DOI: http://dx.doi.org/10.1016/j. ceramint.2013.07.023

17. Loghman-Estarki MR, Hajizadeh-Oghaz M, Edris H, Razavi RS. Comparative studies on synthesis of nanocrystalline $\mathrm{Sc}_{2} \mathrm{O}_{3}-\mathrm{Y}_{2} \mathrm{O}_{3}$ doped zirconia (SYDZ) and YSZ solid solution via modified and classic Pechini method. CrystEngComm. 2013;15:5898-5909. DOI: http://dx.doi.org/10.1039/c3ce40288f
18. Loghman-Estarki MR, Edris H, Razavi RS. Large scale synthesis of non-transformable tetragonal $\mathrm{Sc}_{2} \mathrm{O}_{3}, \mathrm{Y}_{2} \mathrm{O}_{3}$ doped $\mathrm{ZrO} 2$ nanopowders via the citric acid based gel method to obtain plasma sprayed coating. Ceramics International. 2013;39(7):7817-7829. DOI: http://dx.doi.org/10.1016/j. ceramint.2013.03.042

19. Kiisk V, Lange S, Utt K, Tätte T, Mändar H, Sildos I. Photoluminescence of sol-gel-prepared hafnia. Physica B: Condensed Matter. 2010;405(2):758-762. DOI: http://dx.doi. org/10.1016/j.physb.2009.09.101

20. Petrik NG, Taylor DP, Orlando TM. Laser-Stimulated Luminescence of Yttria-Stabilized Cubic Zirconia Crystals. Journal of Applied Physics. 1999;85(9):6770-6776. DOI: http:// dx.doi.org/10.1063/1.370192

21. Suresh S, Arunseshan C. Dielectric Properties of Cadmium Selenide (CdSe) Nanoparticles synthesized by solvothermal method. Applied Nanoscience. 2014;4(2):179-184. DOI: http:// dx.doi.org/10.1007/s13204-012-0186-5

22. Suresh S. Synthesis, structural and dielectric properties of zinc sulfide nanoparticles. International Journal of Physical Sciences. 2013;8(21):1121-1127.

23. Suresh S. Studies on the dielectric properties of CdS nanoparticles. Applied Nanoscience. 2014;4(3):325-329. DOI: http://dx.doi. org/10.1007/s13204-013-0209-x

24. Suresh S, Podder J, Das I. Hydrothermal Synthesis of Zirconium Oxide Nanoparticles and its Characterization. Journal of Materials Science: Materials in Electronics. 2016;27(6):5622-5627. 